\title{
Images of women in STEM fields
}

\author{
S. Cho, M. Goodman, B. Oppenheimer, J. Codling and T. Robinson
}

\begin{abstract}
This study investigated how eighth-grade students perceived images of women in STEM and non-STEM careers. Thirty-six images were posted on-line; we measured five characteristics of each image. Forty students participated in the study. We found that there were significant differences in attractiveness, creativity, and intelligence between STEM and non-STEM images. There were no significant differences for good at her job and organization. In addition, there were no significant differences among STEM and non-STEM images of women of the same race.
\end{abstract}

\section{Introduction}

Efforts to increase the number of white women, African-American men and women, and Hispanic men and women entering careers in STEM (science, technology, engineering, and mathematics) fields have stalled in the United States after initial success. Instead, white males and Asians continue to obtain careers in the high paying STEM fields while most women and other minorities earn the lower wages associated with professions in the arts, humanities, social sciences, and education.

STEM careers usually require high levels of proficiency in mathematics and the sciences prior to college enrollment. Students entering college with only basic science backgrounds and algebraic skills are unlikely to become engineering, science, or computer majors, due to the fact that calculus, physics, and chemistry are foundational courses. Accordingly, the decisions made by middle school students whether to take pre-algebra or basic mathematics may determine if they will ever have the opportunity to enter the STEM fields.

While considering these assumptions, we have conducted two studies in a university community in the American South. Our first study (Oppenheimer et al., 2008) was conducted at a majority AfricanAmerican public school among eighth graders to learn what the students' perceptions were of women and African-Americans in STEM fields [1]. In this paper we describe a second study of eighth graders at a majority white private school in the same community. Our research should help us design better interventions to encourage girls and minority students to enter STEM career fields.

\section{Literature review}

Mary Ellen Smyth, past president of the AAUW Educational Foundation, has identified why many girls do not consider careers in STEM fields. "The good news is that women have made great strides in education and the work force. The bad news is that the new high-tech economy is leaving women behind." Smyth said, "It's not that women are hitting a glass ceiling in the high-tech sector. It's that they don't have the keys to open the door." [2] The AAUW received its fourth grant to study STEM issues. "Our report will sound the alarm," said AAUW Executive Director Linda D. Hallman. "As a nation, we can't afford to take baby steps toward achieving parity, especially when we're facing a shortage of professionals in the STEM fields. How can we stay competitive in the global economy when half of our population isn't fully engaged in those areas?" [3]

According to the National Science Foundation (NSF), women earned $57.6 \%$ of bachelor degrees between 2002 and 2004. However, women earned less than 40\% of the degrees in STEM fields. [4] Similarly, an NSF priority is to increase the number of minorities entering STEM fields. AfricanAmericans, Latinos, and Native Americans receive 30\% of undergraduate degrees in the U.S., but only $12 \%$ of engineering degrees are earned by these minority groups, reports Nagel. Nagel cites a report from 
the National Action Council for Minorities in Engineering that indicates the percentage for AfricanAmericans declined from $3.3 \%$ to $2.5 \%$ between 1995 and 2005 [5].

Eccles, who has conducted studies of STEM trends, reports the number of women enrolled in engineering programs increased from $3 \%$ in the 1970 s to $18 \%$ in the $1990 \mathrm{~s}$. [6] According to AAUW numbers, the percentage of women in engineering/architecture is $14 \%$, computer science $26 \%$, and research, science, and technology $38 \%$. Women compose $71 \%$ of the work force in education and $67 \%$ in clerical support. According to U.S. Census data compiled in 2005, the proportion of women in mechanical engineering is $5.8 \%$, civil engineering is $13.2 \%$, and industrial engineering is $14.9 \%$. [7]. The New York Times reported that the percentage of women in computer science has dropped from $28 \%$ to $22 \%$ between 2001 and 2004 [8].

"Gender role socialization and commonly held stereotypes about gender differences in 'natural talents' for various subject areas are likely to lead females and males to have different estimates of their own personal efficacies for physical science and engineering," explains Eccles. Careers that emphasize "people and social interactions" are considered more appropriate for females; careers requiring physical activities or abstractions are culturally assigned to males in America. Accordingly, "gender role socialization is likely to lead to gender differences" in careers selected by men and women, continues Eccles. Furthermore, she says women do not consider the full range of career possibilities. Instead, American women enter traditional fields, such as teaching, nursing, and clerical work. Even when women go into the STEM fields, they continue to pick care giving careers, such as primary care medicine, pharmacy, and psychology [9].

The purpose of our study is to measure stereotypes held by eighth graders about women in STEM and non-STEM careers.

H1. There will be a difference in how eighth graders will rate images of women in non-STEM careers than how they will rate women in STEM careers. The research conducted by Smyth and Eccles predicts that eighth graders should have positive views of women in non-STEM fields and negative views of women in STEM fields. If these results occur, it would help explain the cultural perspectives leading to the results found by the AAUW and NSF.

H2. There will be a difference in how eighth graders will rate images of African-American women in non-STEM careers than how they will rate African-American women in STEM careers. The report by the National Action Council for Minorities in Engineering predicts that participants in the survey would have negative attitudes towards African-Americans in STEM careers, but would have more positive views of African-Americans in non-STEM careers.

H3. There will be a difference in how eighth graders will rate images of white women in non-STEM careers than how they will rate white women in STEM careers.

\section{Method}

\subsection{Sample}

We obtained permission from the governance board of a private academy in a university community in the American South to run the study among all eighth graders at the school. Consent forms were sent home to parents and forty white students returned the forms and participated in this study. Males composed $45 \%$ of the study group and females, $55 \%$.

\subsection{Procedure}

We posted the survey on SurveyMonkey.com. Students accessed the survey from a school lab, and were placed in two different groups. One group (19) took the STEM survey and the other group (21) took the non-STEM survey to balance the numbers. The STEM survey was composed of 36 images, each labeled with a job title associated with a career in a STEM field. The non-STEM survey was exactly the same, except the job titles were associated with careers in non-STEM fields. Respondents were asked to rate the images based on their perceptions by answering five questions per image. 


\subsection{Measurement}

STEM/Non-STEM Images. Most of the women who agreed to be photographed for our study were students at two universities in nearby communities in the American South. Our photographs included women who placed themselves in three body image categories (dress size $<8,8-14,>14$ ) and in three age categories $(<25,25-35,>35)$. One-half of the women were African-American and one-half were white. The survey included pictures of women in each group. Each woman was photographed in street clothing from a neutral camera position. All images were 150 pixels wide on the survey.

Perception of STEM/Non-STEM Image. Our study asked the participants to answer five questions about each image. Our survey used five questions from a previous STEM study (Oppenheimer et al, 2008). The five questions were: (a) Would you expect this person to be good at her job? (five-point semantic differential Likert-type scale ranging from not very good to very good); (b) Would you expect this person to be organized? (not very organized to very organized); (c) How would you rate this person's intelligence? (not very intelligent to very intelligent); (d) Do you find this person attractive? (not very attractive to very attractive); (e) Would you expect this person to be creative? (not very creative to very creative).

\section{Results}

H1. A difference in STEM/non-STEM images. Hypothesis one suggested there would be a difference in how participants perceived images of women in non-STEM and STEM careers. We conducted an independent t-test to confirm our hypothesis. Alpha $=.01$. There was a significant difference in intelligence between STEM and non-STEM images $(M=4.40$ vs. $4.10, p<.001)$. For attractiveness, there was a significant difference between STEM and non-STEM images $(M=2.23$ vs. $2.44, p<.01)$. There was also a significant difference in creativity between STEM and nonSTEM images $(M=3.88$ vs. 3.42, $p<.001)$. However, hypothesis one was not confirmed for organization $(M=4.05$ vs. $3.16, p=.24)$ and being good at her job $(M=4.14$ vs. $4.16, p=.82)$.

H2. A difference in African-American women in non-STEM careers and STEM careers. Hypothesis two suggested there would be a difference in how participants perceived African-American women in nonSTEM and STEM careers. We conducted an independent t-test to confirm our hypothesis. Alpha = .01 . This hypothesis was rejected for intelligence, attractiveness, creativity, organization, and being good at her job. There was no significance in how the participants rated African-American images of women, regardless of the career. This hypothesis was refuted. See table 1 below.

\begin{tabular}{|llllll|}
\hline Items & & Mean & SD & $t$ & Sig. \\
\hline Good at job & STEM & 3.92 & .83 & -.54 & .59 \\
& Non-STEM & 4.07 & .83 & & \\
\hline Organized & STEM & 3.79 & .73 & -.30 & .76 \\
& Non-STEM & 3.86 & .81 & & \\
\hline Intelligent & STEM & 4.19 & .82 & .38 & .70 \\
& Non-STEM & 4.09 & .77 & & \\
\hline Attractive & STEM & 2.05 & .80 & -.64 & .52 \\
& Non-STEM & 2.22 & .84 & & \\
& & & & & \\
\hline Creative & STEM & 3.70 & .91 & .83 & .40 \\
& Non-STEM & 3.45 & .97 & & \\
\hline
\end{tabular}

Table 1. Mean difference in African-American women's images in non-STEM careers and STEM careers.

H3. A difference in how eighth graders will rate images of white women in non-STEM careers than how they rate white women in STEM careers. Hypothesis three argues there will be a difference in how participants perceive white women in non-STEM and STEM careers. We conducted an independent t-test to confirm this hypothesis. Alpha $=.01$. This hypothesis was rejected for intelligence, attractiveness, creativity, organization, and being good at her job. There was no significant difference in how the participants rated images of white women, regardless of the career. This hypothesis was rejected (see table 2). 


\begin{tabular}{|llllll|}
\hline Items & & Mean & SD & t & Sig. \\
\hline Good at job & STEM & 4.30 & .75 & .30 & .62 \\
& Non-STEM & 4.43 & .90 & & \\
\hline Organized & STEM & 4.22 & .69 & .40 & .68 \\
& Non-STEM & 4.12 & .84 & & \\
\hline Intelligent & STEM & 4.54 & .61 & .36 & .17 \\
& Non-STEM & 4.22 & .82 & & \\
\hline Attractive & STEM & 2.40 & .87 & .38 & .27 \\
& Non-STEM & 2.73 & 1.0 & & \\
& & & & & .11 \\
\hline Creative & STEM & 4.04 & .83 & .81 & .85 \\
& Non-STEM & 3.61 & & \\
\hline
\end{tabular}

Table 2. Mean difference in white women's images in non-STEM careers and STEM careers.

\section{Discussion}

In this study of a private school in a university community in the American South, the students were all white; in our previous study of a public school in the same town, a majority of students were AfricanAmerican. We have little difference in results between the two populations. Since all the participants in the two studies were raised in the same community, the lack of difference between the two populations indicates that African-American children did not consider the images of women differently than white students in terms of STEM stereotypes. We did determine students at the private school found images of white women consistently more attractive than images of African-American women. The private school students rated the white women more attractive than the African-American women in 30 of 36 images.

In our analysis, the results from $\mathrm{H} 1$ indicate a somewhat complex picture of how these participants viewed women in STEM and non-STEM careers. The students found the images of women in STEM career fields to be significantly more intelligent, significantly more creative, and significantly less attractive than images of women in non-STEM career fields. These results suggest that the participants accepted a stereotypical view of women in STEM careers vs. non-STEM careers. To the degree that the students accept the STEM stereotypes, we would expect the males at the private academy to consider STEM careers (science, technology, engineering, and mathematics), while females would pursue careers in non-STEM fields (education, social sciences, art, and humanities). These results suggest intervention strategies targeted to students before eighth grade could impact high school course selections significantly. The time to convince underrepresented populations that STEM careers are open to them is before eighth grade.

One limitation of this study is that we were not able to obtain validity because students had only a limited time to take the survey; accordingly, we had to limit the number of questions to five and the number of images to 36. Also, our population size was small and the race of the sample was homogenous. In the future, we will administer the same survey to university students to see if they maintain the same stereotypes found among the eighth graders.

\section{Conclusion}

Women and minorities have been underrepresented in the STEM fields. Even though we may encourage our daughters to become doctors and scientists, by the time they graduate from high school they have made up their minds to stay clear of the fields that they perceive as less feminine, which includes STEM fields. Even though we claim that minority youth can be anything they want to be, by the time they graduate, minorities see the STEM fields as a club that is not open to them. If we could find an age where intervention strategies would be most effective, perhaps we could change the perception of STEM fields to make them more acceptable to young women and minorities. So, for this study, our research group focused on the perceptions of eighth graders. During this study, we desired to grasp an understanding about how eighth graders initially perceived the images of white women and black women as related to STEM careers and non-STEM careers.

It is imperative that all youth, regardless of their gender, race, or nationality, be exposed to educational opportunities and encouraged to pursue career paths that will prepare them to make use of their abilities. 
The theory for our study followed the premises that, to significantly impact a student's behavior patterns, intervention strategies must be implemented prior to the eighth grade.

In many ways, this theory presented itself as a reasonable assumption because most students remain impressionable and receptive to the influence of authoritative figures such as parents, grandparents, teachers, ministers, law enforcement personnel, and other positive examples of community leadership. Furthermore, an age period prior to the eighth grade may provide an occasion where students have not been contaminated by the negative influence of their peers or society to prevent them from enrolling into pre-algebra and other advanced mathematics and science courses that will better prepare them for a STEM field career.

Our results indicate that our study sample was beginning to think in stereotypical patterns. Accordingly, intervention strategies that targeted students before eighth grade could impact high school course selections significantly. The time to convince underrepresented populations that STEM careers are open to them is before eighth grade.

\section{Notes and references}

[1] B. Oppenheimer, S-H. Cho, M. Goodman, J. Codling, T. Robinson and T. Wheeler, STEM Images, presented at Louisiana/Mississippi Section of the Mathematical Association of America, Lake Charles, LA, February 2008.

[2] American Association of University Women, Study: Women Concentrated in 'Pink-Collar' Jobs, May 6, 2003, available at: http://hr.blr.com/news.aspx?id=8444

[3] L. Goodnight, AAUW to Launch Major STEM Study with Funding from National Science Foundation, News release, AAUW, Oct 16, 2008.

[4] National Science Foundation, Program Provides Blueprint for Recruiting Minorities to Science and Engineering, Sept 26, 2007, available at: http://www.nsf.gov/news/news_summ.jsp?cntn_id=110124

[5] D. Nagel, Report: STEM Gap Widens for Underrepresented Minorities, T.H.E. Journal, May 2008, available at: http://campustechnology.com/Articles/2008/05/Report-STEM-Gap-Widens-for-Underrepresented-Minorities.aspx

[6] J.S. Eccles (1993), Parents and gender-role socialization during the middle childhood and adolescent years, in S. Oskamp and M. Costanzo eds., Gender Issues in Contemporary Society, London, Sage Publications.

[7] AAUW (March, 2009), Breaking through barriers for women and girls, available at http://130.18.140.19/STEM/2009ppt.pdf, pg 6.

[8] R. Stross, Digital Domain: What Has Driven Women Out of Computer Science?, The New York Times, Nov 15, 2008. Available at: http://www.nytimes.com/2008/11/16/business/16digi.html

[9] J.S. Eccles, Parents and gender-role socialization.

\section{Authors}

Seung-Ho Cho holds a Ph.D. degree from University of Alabama. He is currently an assistant professor of communication at Mississippi State University. He has studied public image and public relations, advertising, and integrated marketing communication. E-mail: shcho72@gmail.com.

Mark Goodman is a professor of communication at Mississippi State University. He studies media effects. E-mail: mg654460@yahoo.com.

Bonnie Oppenheimer is a professor of mathematics at Mississippi University for Women. She has studied women's images in the media, and attitudes and skills among elementary school teachers.

E-mail: boppenheimer@as.muw.edu.

James Codling is an instructor of philosophy and religion at MSU. As are all of the authors, he is part of research group that studies media and the images of women. E-mail: jcodling@trinitysem.edu.

Thomas Robinson is a graduate student at MSU and an employee of the Social Science Research Center at MSU. E-mail: Thomas.Robinson@SSRC.MsState.Edu.

How to CITE: $\quad$ S. Cho, M. Goodman, B. Oppenheimer, J. Codling and T. Robinson, Images of women in STEM fields, Jcom 08(03) (2009) A03. 